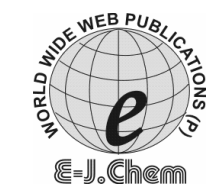

http://www.e-journals.net
ISSN: 0973-4945; CODEN ECJHAO

E-Journal of Chemistry

2009, 6(S1), S496-S500

\title{
New Spectrophotometric Method for Determination of Cadmium
}

\author{
K. S. PARIKH ${ }^{*}$, R. M. PATEL and K. N. PATEL ${ }^{\#}$ \\ Department of Chemistry \\ Sheth M.N. Science College, North Gujarat, Patan- 384265, India. \\ "Shri U.P.Arts, Smt.M.G.Panchal Science and V.L.Shah Commerce College, \\ Pilvai-382 850, India. \\ ksparikh64@yahoo.co.in
}

Received 12 April 2009; Accepted 5 June 2009

\begin{abstract}
The reagent 2-hydroxy-4- $n$-butoxy-5-bromopropiophenone thiosemicarbazone (HBBrPT) has been used for the determination of $\mathrm{Cd}(\mathrm{II})$ by using spectrophotometric method. The reagent HBBrPT gave an intense yellow colour with $\mathrm{Cd}$ (II) solution in basic medium. The maximum absorbance was observed at $440 \mathrm{~nm}$, in basic buffer solution ( $\mathrm{pH} 10.00)$. The molor absorptivity and Sandell's sensitivity of Cd(II)-HBBrPT complex were $4035 \mathrm{~mol}^{-1} \mathrm{~cm}^{-1}$ and $0.02765 \mu \mathrm{g} \mathrm{cm}^{-2}$ respectively. The stability constant of 1:2 Cd(II)-HBBrPT complex was $8.46 \times 10^{6}$. The effect of various iron was also studied.
\end{abstract}

Keywords: 2-Hydroxy-4-n-butoxy-5-bromopropiophenone thiosemicarbazone, Spectral study, Spectrophotometric determination, HBBrPT complex.

\section{Introduction}

Thiosemicarbazone are known as analytical reagents ${ }^{1-6}$. The reagents is formed by the condensation of thiosemicarbazide carbonyl compound. Thiosemicarbazones are also found to have biological activity. These compounds contain an azomethine for their reactivity with number of transition metal ions, which from coloured complexes. Further the metal complexes formed with these reagents are of great medicinal value in the treatment of diseases like influenza, protozoa, small pox and certain kinds of tumor ${ }^{7}$. These compounds are known for their antitubercular activity ${ }^{8}$.Metal chelate of there reagent inhibit tumor growth and increase the activity of some drugs ${ }^{9}$. In the treatment of cancer the active species is the metal chelate of thiosemicarbazone ${ }^{10}$. Metal chelates of these compounds are used as pesticides $^{11}$ and fungicidea ${ }^{12,13}$ in agriculture. 


\section{Experimental}

\section{Preparation of $\mathrm{HBBrPT}$}

The reagent 2-hydroxy-4-n-butoxy-5-bromopropiophenone thiosemicarbazone was prepared by simple condensation of 2-hydroxy-4- $n$-butoxy-5-bromopropiophenone with thiosemicarbazied by adopting the standard procedures. The structure of the compound is given below (I).<smiles>CCCCOc1cc(O)c(/C(CC)=N/NC=S)cc1Br</smiles>

HBBrPT

Scheme 1. 2-Hydroxy-4-n-butoxy-5-bromopropiophenone thiosemicarbazone.

The structure has been established based on IR, NMR and Mass spectra. The melting point of $\mathrm{HBBrPT}$ is $108-109^{\circ} \mathrm{C}$.

\section{Solution preparation}

Buffer solutions were prepared using $\mathrm{HCl}, \mathrm{CH}_{3} \mathrm{COOH}$ and $\mathrm{CH}_{3} \mathrm{COONa}$ in acidic medium and $\mathrm{NH}_{4} \mathrm{OH}, \mathrm{NH}_{4} \mathrm{Cl}$ in basic medium.

\section{Preparation of metal solution and reagent solution}

$\mathrm{Cd}(\mathrm{II})$ solution was prepared using analytical reagent grade cadmium nitrate. The amount of $\mathrm{Cd}(\mathrm{II})$ in this solution was determined volumetrically using EDTA $^{14}$. Appropriate quantity of 2-hydroxy-4-n-butoxy-5-bromopropiophenone thiosemicarbazone was dissolved in benzene for making $0.0005 \mathrm{M}$ reagent solution.

An aliquot of the solution containing $5.62-16.86 \mu \mathrm{g} / \mathrm{mL}$ of $\mathrm{Cd}(\mathrm{II}), 10 \mathrm{~mL}$ of basic buffer solution of the $\mathrm{pH} 10$ and $1 \mathrm{~mL} 0.0005 \mathrm{M}$ 2-hydroxy-4- $n$-butoxy-5-bromopropiophenone thiosemicarbazone was taken in $25 \mathrm{~mL}$ volumetric flask were made upto the mark with distilled water. The absorbance of this solution was measured at $440 \mathrm{~nm}$ against reagent blank.

Shimadzu 160A UV-visible spectrophotometer (Japan) equipped with $1 \mathrm{~cm}$ quartz cell was used in these investigations for making absorbance measurements. A pH meter ELICO L 1-120 (ELICO, Hyderabad) was used to make pH measurements.

\section{Results and Discussion}

$\mathrm{Cd}$ (II) reacts with 2-hydroxy-4- $n$-butoxy-5-bromopropiophenone thiosemicarbazone in basic $\mathrm{pH}$ to give yellow coloured species. The colour reaction of $\mathrm{Cd}(\mathrm{II})$ with the reagent is instantaneous even at room temperature. The absorbance of yellow coloured species at a wavelength corresponding to maximum absorbance i.e. $440 \mathrm{~nm}$ remains constant at least one hour. Studies on the effect of $\mathrm{pH}$ on the absorbance revealed that the maximum colour was formed in a solution of $\mathrm{pH} 10.00$. A ten-fold excess of the reagent was adequate for the complete colour development. Addition of excess of the reagent has no adverse effect on absorbance. The order of addition of various components shows on effect on absorbance values. Physicochemical and analytical characteristic of $\mathrm{Cd}(\mathrm{II})-\mathrm{HBBrPT}$ data shown in Table1.The studies relating to the effect of $\mathrm{Cd}(\mathrm{II})$ related that a linear relationship exists between metal ion concentration and absorbance in the range $5.62-16.86 \mu \mathrm{g} / \mathrm{mL}$, the molorabsorptivity and sandell's sensitivity are $4035 \mathrm{~mol}^{-1} \mathrm{~cm}^{-1}$ and $0.02765 \mu \mathrm{g} \mathrm{cm}$ respectively. 
Table 1. Physicochemical and analytical characteristic of Cd(II)-HBBrPT.

\begin{tabular}{lc}
\hline \multicolumn{1}{c}{ Characteristics } & Results \\
\hline $\mathrm{pH}$ & 10 \\
$\lambda$ max, $\mathrm{nm}$ & 440 \\
Colour & Yellow \\
Molar absorptivity, $\mathrm{L} \mathrm{mole}^{-1} \mathrm{~cm}^{-1}$ & 4035 \\
Sandal's stativity, $\mu \mathrm{g} \mathrm{cm}^{-2}$ & 0.02765 \\
Beer's law validity upto $\mu \mathrm{g} / \mathrm{mL}$ & 28.10 \\
Opt. Conc. Range, $\mu \mathrm{g} / \mathrm{mL}$ & $5.62-16.86$ \\
Stability constant $(\mathrm{k})$ & $8.46 \times 10^{6}$ \\
Standard derivation $(\mathrm{S})$ & 0.299 \\
$\Delta \mathrm{G}^{\mathrm{O}}$, $\mathrm{k} . \mathrm{cal}$ & -12.462 \\
\hline
\end{tabular}

As the metal ion $\mathrm{Cd}(\mathrm{II})$ forms the coloured complex with the reagent, an attempt was made to determine the composition and the stability constant of the complex. The method of Vosburgh and Cooper's ${ }^{15}$ showed that only one complex is formed. To determine the stoichiometry of complex, Job's method ${ }^{16}$ related data is shown in Figure 1 and mole ratio method $^{15}$ is shown in Figure 2 were conducted to make these determinations.

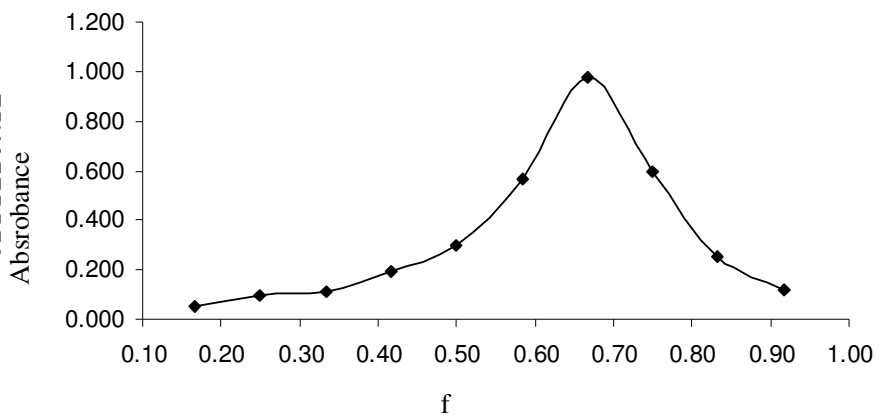

Figure 1. Job's method (Cd(II)-HBBrPT Complex).

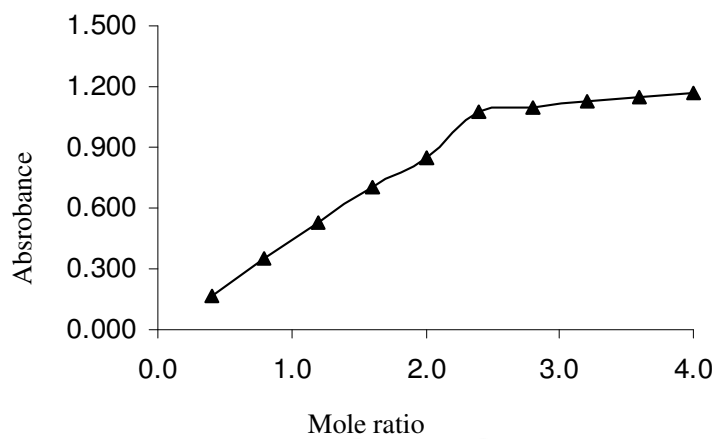

Figure 2. Mole-ratio method (Cd(II)-HBBrPT Complex).

It is noticed that $\mathrm{Cd}(\mathrm{II})$ forms a stable yellow colored 1:2 (metal: ligand) complex with 2-hydroxy-4- $n$-butoxy-5-bromopropiophenone thiosemicarbazone. The stability constant of the complex was found to be $8.46 \times 10^{6}$.

The effect of various ions on the determination of $\mathrm{Cd}(\mathrm{II})$ was studied to find the tolerance levels of this foreign iron the present method the results are presented in Table 2. 
Table 2. Interference of diverse ions.

\begin{tabular}{cccc}
\hline Cations & Tolerance limit, ppm & Anions & Tolerance limit, ppm \\
\hline $\mathrm{Co}^{+2}$ & 10 & $\mathrm{Br}^{-}$ & 500 \\
$\mathrm{~Pb}^{+2}$ & 100 & $\mathrm{Cl}^{-}$ & 100 \\
$\mathrm{Cr}^{+6}$ & 5 & $\mathrm{I}^{-}$ & 50 \\
$\mathrm{Th}^{+2}$ & 50 & $\mathrm{NO}_{3}^{-}$ & 500 \\
$\mathrm{Sm}^{+2}$ & 100 & $\mathrm{CH}_{3} \mathrm{COO}^{-}$ & 10 \\
$\mathrm{Na}^{+}$ & 500 & $\mathrm{SO}^{-2}$ & 500 \\
$\mathrm{~K}^{+}$ & 500 & & \\
$\mathrm{Al}^{+3}$ & 10 & & \\
$\mathrm{Ag}^{+}$ & 50 & & \\
$\mathrm{Pd}^{+2}$ & 100 & & \\
\hline
\end{tabular}

\section{Applications}

The complex formed between cadmium and 2-hydroxy-4-n-butoxy-5-bromopropiophenone thiosemicarbazone is stable and can be used for analysis. The method has been applied for the analysis of synthesized mixtures containing Cd(II). The related data is shown in Table 3.

Table 3. Analysis of synthetic mixture.

\begin{tabular}{cc}
\hline Amounts taken, $\mu \mathrm{g}$ & Found*, $\mu \mathrm{g}$ \\
\hline 250 & 250.57 \\
310 & 310.19 \\
190 & 191.87 \\
\hline
\end{tabular}

\section{Conclusions}

*Average value of three determinations

Cd(II) forms a 1:2 stable yellow colored complex with 2-hydroxy-4- $n$-butoxy-5bromopropiophenone thiosemicarbazone. This complex was used for the determination of cadmium in microgram quantities. The stability constant of the complex is $8.46 \times 10^{6}$. The molar absorptivity and Sandell's sensitivity are $4035 \mathrm{~mol}^{-1} \mathrm{~cm}^{-1}$ and $0.02765 \mu \mathrm{g} \mathrm{cm}^{-2}$ respectively. The method has been applied for the analysis of cadmium in synthesized mixtures and also in alloys.

\section{Acknowledgement}

The authors are thankful to Sheth M.N. Science College, Patan for providing laboratory and library facilities. We are highly thankful to UGC, Pune for providing MRP to K.S. Parikh.

\section{References}

1. Singh R B, Garg B S and Singh R P, Talanta, 1978, 25, 619.

2. Reddy K G, Hussain Reddy K and Reddy D V, Indian J Chem., 1986, 25(A), 982.

3. Stankoviansky S, Carsky J and Beno A, Chim Zvesti., 1979, 23, 589.

4. Patel B H, Shah J R and Patel R P, J Indian Chem Soc., 1975, 52, 998.

5. Vogel A I, A textbook of quantitative inorganic analysis, $3^{\text {rd }}$ Edn., Longman, London, 1971, 34, 40.

6. Robinson R and Shah R C, J Chem Soc., 1934, 149.

7. Patering H C, Buskirk H H and Underwod G E, Cancer Res., 1964, 64, 367.

8. Zapafonetis C I and Kalas J P, Proc Soc Expt Biol Med., 1965, 105, 560.

9. Dwyer F P, Maythew F and Shulman A, Br J Cancer, 1965, 19, 195. 
10. Gim J A and Pantering H G, Cacenr Res., 1967, 27, 1248.

11. Libermeister Z, Naturforsh, 1950 B5, 79.

12. Johnson C W, Joyner J W and Perry R P, Antibiotics Chemotherapy, 1952, 2, 636.

13. Sulekh Chandra and Monka tyagi, J Indian Chem Soc., 2008, 85, 42-47

14. Vosburgh W C and Iron G R, J Am Chem Soc., 1941, 63, 437.

15. Job P, Ann Chem., 1938, 115, 332.

16. Yoe J H and Jones A L, Ind Eng Chem Anal Ed.,1944, 16, 111. 


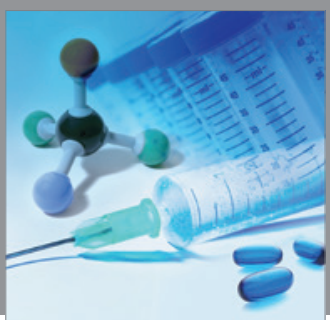

International Journal of

Medicinal Chemistry

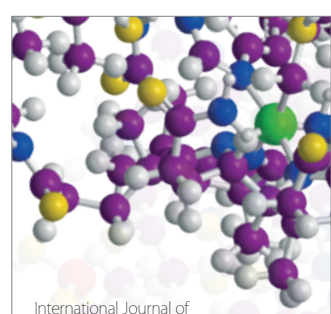

Carbohydrate Chemistry

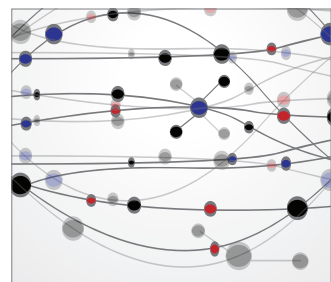

The Scientific World Journal
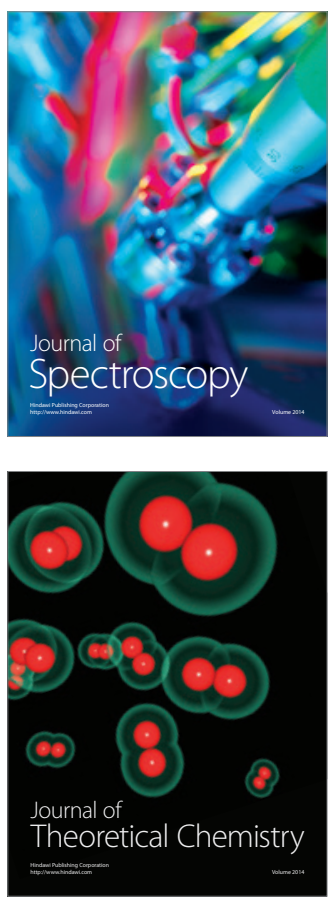
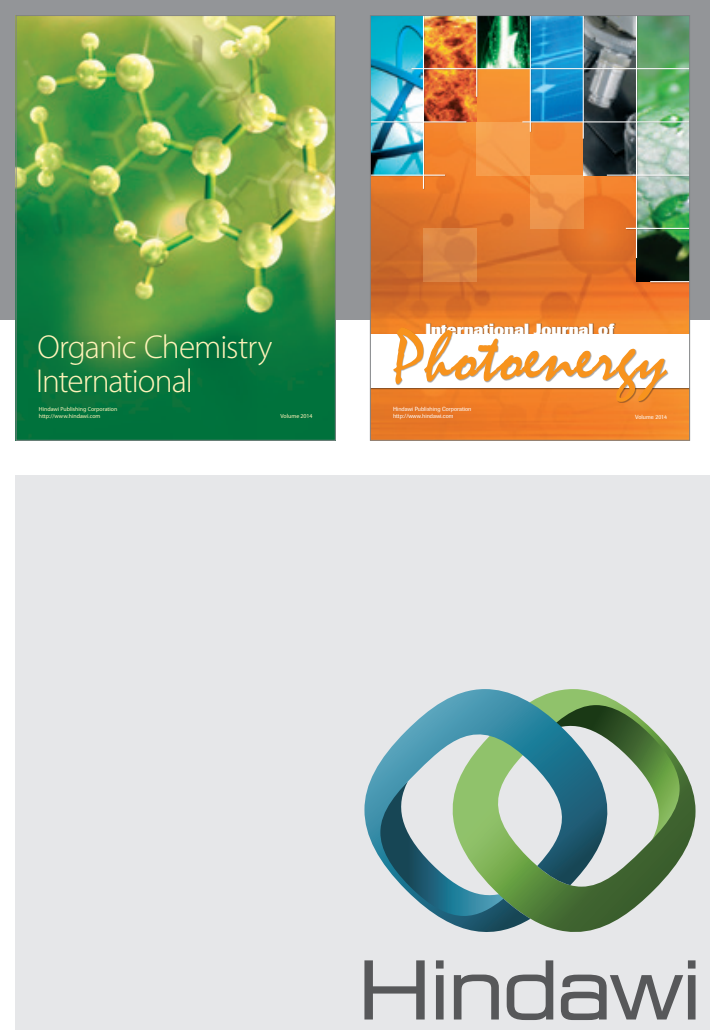

Submit your manuscripts at

http://www.hindawi.com
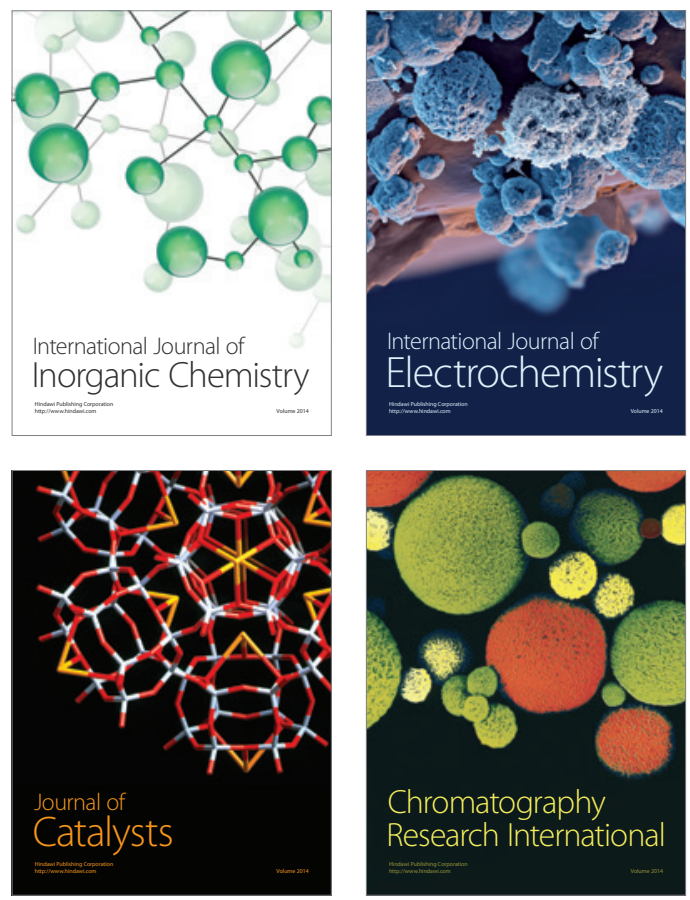
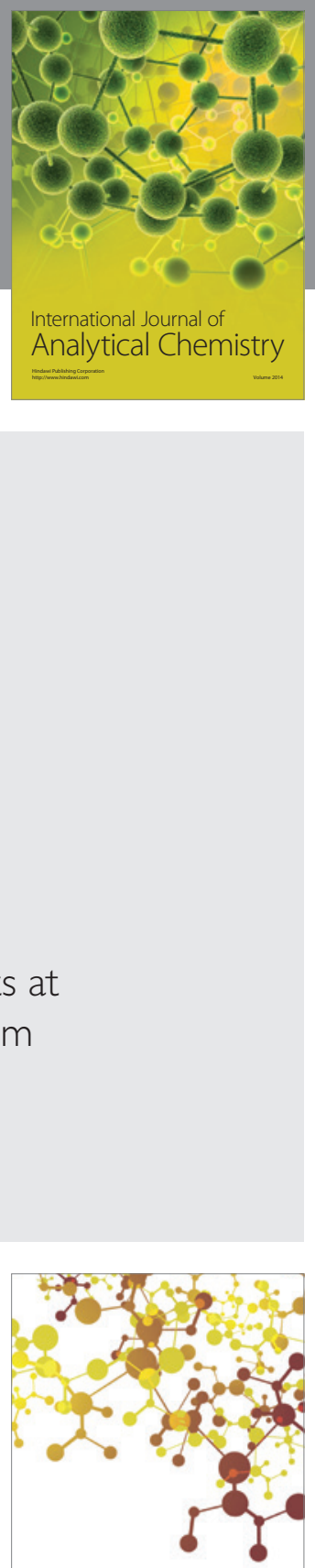

Journal of

Applied Chemistry
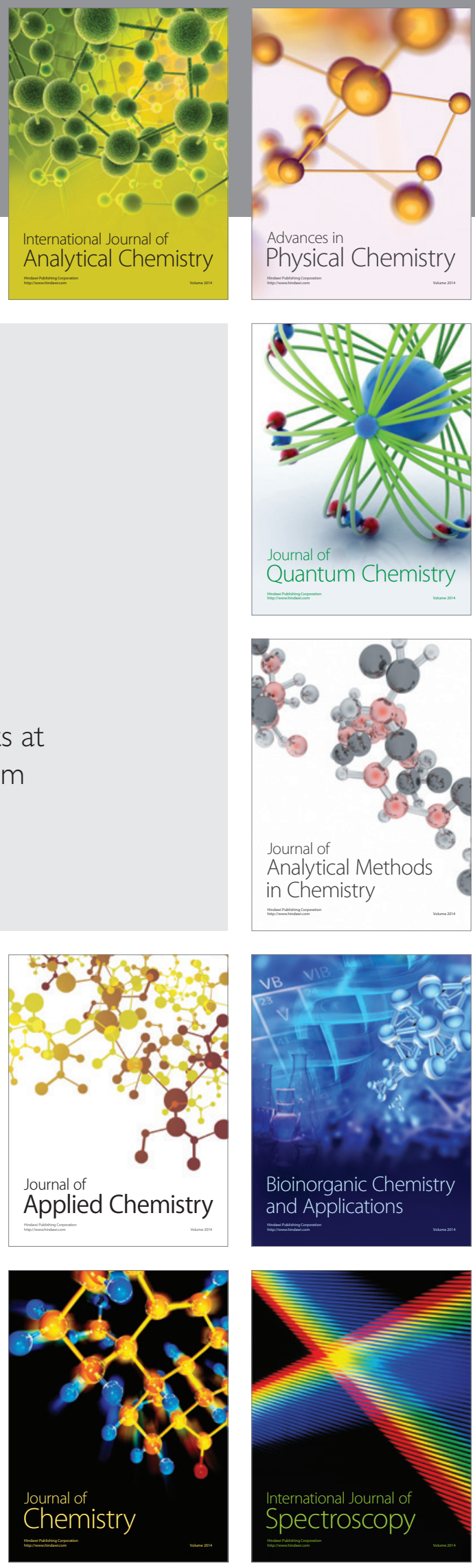